\title{
Fate of Grape-derived Terpenoids in Model Systems Containing Active Yeast
}

Cells

Davide Slaghenaufi, Carla Indorato, Eleonora Troiano, Giovanni Luzzini, Giovanna E. Felis, Maurizio Ugliano* University of Verona, Department of Biotechnology, Villa Lebrecht, via della Pieve 70, 37029 San Pietro in Cariano, Italy

*Corresponding author: maurizio.ugliano@univr.it 
Supplementary

S.1. Calculated polarity of studied compounds

\begin{tabular}{cc}
\hline \hline & $\begin{array}{c}\text { Calculated } \\
\text { LogP }\end{array}$ \\
\hline Mintlactone & 1.83 \\
Camphor & 2.13 \\
a-Terpineol & 2.79 \\
Terpinen-4-ol & 2.99 \\
Menthol & 3.2 \\
Piperitone & 2.41 \\
Linalool & 3.28 \\
$\boldsymbol{\beta}$-Citronellol & 3.38 \\
Geraniol & 3.28 \\
Nerol & 3.28 \\
Farnesol & 5.31 \\
Bisabolol & 5.07 \\
p-Cymene & 4.02 \\
Myrcene & 4.58 \\
$\boldsymbol{\alpha}-$ Phellandrene & 4.43 \\
Terpinolene & 4.67 \\
Limonene & 4.45 \\
\hline \hline
\end{tabular}

